NASA Technical Memorandum 88922

AIAA-87-0056

\title{
Spatially Growing Disturbances in a High Velocity Ratio Two-Stream, Coplanar Jet
}

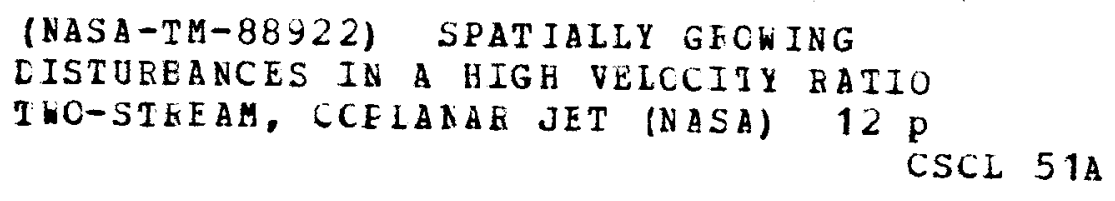

Jeffrey H. Miles

Lewis Research Center

Cleveland, Ohio

Prepared for the 25th Aerospace Sciences Meeting sponsored by the American Institute of Aeronautics and Astronautics Reno, Nevada, January 12-15, 1986

\section{NMSN}


SPATIALLY GROWING DISTURBANCES IN A HIGH VELOCITY RATIO TWO-STREAM, COPLANAR JET

\author{
Jeffrey $H$. Miles \\ National Aeronautics and Space Administration \\ Lewis Research Center \\ Cleveland, Ohio 44135
}

\begin{tabular}{|c|c|}
\hline & Abstract \\
\hline $\begin{array}{l}\text { The } \\
\text { flow on } t \\
\text { jet havin } \\
\text { for a nom } \\
0.68 \text { was } \\
\text { earized } \\
\text { erties of } \\
\text { order azi } \\
\text { found tha } \\
\text { two-strea } \\
\text { very diff } \\
\text { and a two } \\
\text { number he } \\
\text { for a fan } \\
\text { x/D = } 1 \\
\text { velocity } \\
\text { stream wi } \\
\text { instabili } \\
\text { frequency } \\
\text { (m=0) } 0 \\
\text { have simi } \\
\text { ity ratio } \\
\text { O.3 the } 9 \\
\text { mode (m }= \\
\text { hot secon } \\
\text { velocity } \\
\text { for the } c \\
\end{array}$ & $\begin{array}{l}\text { influence of cold and heated secondary } \\
\text { he instability of a two-stream, coplanar } \\
\text { a } 0.7 \text { Mach number heated primary jet } \\
\text { inal fan to primary velocity ratio of } \\
\text { investigated by means of inviscid lin- } \\
\text { tability theory. The instability prop- } \\
\text { spatially growing axisymmetric and first } \\
\text { muthal disturbances were studied. It was } \\
\text { the instability characteristics of the } \\
\text { m jet with a velocity ratio of } 0.68 \text { are } \\
\text { erent from those of a single stream jet, } \\
\text {-stream, coplanar jet having a } 0.9 \text { Mach } \\
\text { ated primary jet and a cold secondary jet } \\
\text { to primary velocity ratio of } 0.30 \text {. For } \\
\text { and in comparison to the case where the } \\
\text { ratio was } 0.3 \text {, the presence of the fan } \\
\text { th a velocity ratio of } 0.68 \text { enhanced the } \\
\text { ty of the jet and increased the unstable } \\
\text { range. However, the axisymmetric mode } \\
\text { nd the first order azimuthal mode (m }=1 \text { ) } \\
\text { lar spatial growth rates where the veloc- } \\
\text { is } 0.68 \text { while for a velocity ratio of } \\
\text { rowth rate of the first order azimuthal } \\
1) \text { is greater. Comparing the cold and } \\
\text { dary flow results showed that for a } \\
\text { ratio of } 0.68 \text { the growth rate is greater } \\
\text { ase with cold secondary flow. } \\
\text { Nomenclature }\end{array}$ \\
\hline $\mathrm{a}$ & speed of sound, $\mathrm{m} / \mathrm{s}$ \\
\hline B & see Eq. (1) \\
\hline$c_{\mathrm{ph}}$ & phase speed, $\mathrm{m} / \mathrm{s}$ \\
\hline$F(r, B, \delta)$ & radial profile term \\
\hline$f$ & eigenfunction \\
\hline$G(r)$ & velocity profile shape \\
\hline$H(\alpha)$ & eigenvalue equation \\
\hline $\mathbf{i}$ & $\sqrt{-1}$ \\
\hline m & azimuthal wavenumber \\
\hline$p(r)$ & pressure \\
\hline $\mathrm{R}$ & radius \\
\hline$r$ & radial position \\
\hline$T(r)$ & static temperature \\
\hline $\mathrm{t}$ & time, sec \\
\hline $\bar{U}_{c l x}$ & $\begin{array}{l}\text { mean velocity on centerline at a given } \\
x / D_{p}\end{array}$ \\
\hline$u, v, w$ & velocity components \\
\hline
\end{tabular}

$\mathrm{X}$

$\alpha$

B

$\Delta \mathrm{u}$

$\delta$

$\theta$

$\lambda$

$\rho$

$\varphi$

\section{Subscripts:}

c

c $7 x$

e

h

i

p

$r$

$\mathrm{S}$

$t$

0

$\infty$

Superscript:
()$^{\prime}$
small disturbance
(-) mean value

axial position

radian frequency

see Eq. (1)

see Eq. (8)

density

compressible exterior solution

meeting point

imaginary

primary jet

real

interior solution

ambient complex eigenvalue wavenumber

velocity difference, $\bar{U}_{c 1 x}-\bar{U}_{\infty}$

momentum boundary layer thickness

cylindrical angular coordinate center line at a given $x / 0_{p}$ position

secondary or fan jet

temperature related

For many future aircraft, improvements in operation will be in part due to control and modification of jet exhaust velocity and/or temperature characteristics. For example, the jet velocity and temperature impinging in the flap surfaces of a short takeoff and landing aircraft employing an under-the-wing blown flap for 1 ift augmentation during takeoff and landing must be controlled in order to maintain flap loads and surface temperatures within acceptable limits for reasons of structural integrity and high-lift performance. Commercial supersonic transports and transatmospheric vehicles are other examples of future aircraft for which changes in the jet exhaust velocity and temperature 
may be important since the jet exhaust noise must be reduced to achieve acceptable community noise levels. Coannular nozzles, mechanical suppressors, and thermal acoustic shields have successfully reduced jet noise.

Temperature and velocity control is usually achieved through jet mixing with the surrounding medium. Normally, mixing is achieved using complex nozzle or shroud/ejector geometries with consequent weight penalties. Enhanced mixing using acoustic or aero/mechanical perturbing devices may reduce this weight penalty. Other situations where acoustic and aero/mechanical excitation may be beneficial are discussed in Ref. 1. Due to these possible benefits the NASA Lewis Research Center has been supporting experimental, numerical, and theoretical research programs in this area. $2-8$

The effect of excitation on centerline velocity and static temperature decay for a single plume jet was estimated using correlation methods in Ref. 9. Some of the data used in these correlations is from the results of the comprehensive experimental and theoretical research program presented in Refs. 2 to 6 which included both hot and cold flows. Additional cold flow results are reported in Ref. 8. As part of a program to obtain similar information for mixing jets, the unexcited velocity and temperature characteristics of twostream coplanar jet exhaust plumes was investigated in Ref. 10. In addition to information on axial velocity and temperature decay, Ref. 10 also presents typical radial velocity and temperature profiles. In an earlier paper, the influence of the second stream on the instability of a two-stream, coplanar jet with only the primary stream heated for a nominal secondary to primary velocity ratio of 0.3 was investigated. 11 In the present paper, the radial velocity and temperature profiles for a secondary to primary velocity ratio of 0.68 for hot and cold secondary flow are used to determine the phase speed and spatial growth rate of pressure instability waves.

An excellent review of recent research on the instability of spatially growing disturbances in the free boundary layer of a jet having a single inflection point was presented by Michalke.12

The two-stream coplanar jet studied herein has two inflection points. As far as the author can determine, little work has been done to study free shear layers with two inflection points. 13 However, the instability of a circular incompressible jet with external flow was analyzed by means of linearized stability theory by Michalke and Herman. 14 For the Mach number range of the present study (around $M=0.7$ ) the flow is compressible. The instability of spatially growing disturbances propagating isentropically in a circular jet for flow in this Mach number range was studied by Michalke 15 and Morris. 16

In this study viscous effects and effects due to the slowly diverging jet flow $17-19$ are neglected. Furthermore, the analys is follows that of Michalke 15 where it was assumed that disturbances propagate isentropically. Because the large scale structure of turbulence in a circular jet is dominated by the axisymmetric and first order azimuthal components, 20 the stability calculations are restricted to these two components. Since the 1 ong term behavior of the disturbances depends on only the most rapidly growing spatial modes, information will be presented only on this type of disturbance.

\section{Theory}

Jet Velocity and Temperature Characteristics

In order to determine the stability of the disturbances, the radial distribution of mean velocity and temperature in the two-stream axisymmetric jet must be specified. The conditions selected for study are among the cases presented in Ref. 10 as being typical. For these cases the nominal primary jet Mach number is 0.7 , the nominal fan-to-primary velocity ratio is 0.68 and the primary stream is heated. The nozzle used for this case had a secondary to primary flow area ratio of 1.9 since the primary nozzle diameter is $10 \mathrm{~cm}$, the secondary nozzle diameter is $17.6 \mathrm{~cm}$, and the primary nozzle thickness is $0.46 \mathrm{~cm}$. The actual velocities and temperatures are shown in Table I. In Table I(a) the case with the cold secondary is shown while in Table I(b) the case with the hot secondary is presented.

The velocity and temperature profiles were constructed using a basic profile shape. The same method was used in Ref. 11. The basic profile used is

$$
F(r, B, \delta)=\frac{1}{2}\left\{1+\tanh \left[B\left(1-\frac{r}{\delta R_{p}}\right)\right]\right\}
$$

where the constants $B$ and $\delta$ are determined from experimental data. The constants used were determined by curve fitting data given in Ref. 10 and they are shown in Table I. Measured and calculated velocity and temperature profiles are compared in Figs. 1 and 2 .

It was found that a reasonable curve fit to the experimental velocity profile could be achieved by adding together two separate profiles specified by Eq. (1) with appropriate constants and appropriate weighting coefficients. The resulting equation for the curve fit to the velocity profile is

$G_{U}(r)=\left(1-\frac{U_{s}}{U_{p}}\right) F\left(r, B_{U_{p}}, \delta_{U_{p}}\right)+\frac{U_{s}}{U_{p}}\left(F r, B_{U_{s}}, \delta_{U_{S}}\right)(2)$

Near the nozzle where the velocity profile for the primary and secondary jets have a top hat profile the values of $B$ are large $\left(B_{U_{p}}=10\right.$ and

$B_{U_{S}}=20$ ) and $G_{U}(0)$ is unity. However, at large

$x / D$ the profiles are broad and the values of $B$ are nearer unity. In this region at $r=0$ the value of $G(0)$ is not unity. Since the actual velocity profile must at $r=0$ have a value of unity, the basic shape is normalized by dividing by $G_{U}(0)$. Thus the actual velocity profile used is

$$
\frac{\bar{U}(r)}{\bar{U}_{C l X}}=\frac{G_{U}(r)}{G_{U}(0)}
$$


where $\bar{U}_{c l x}$ is the mean velocity on the center1 ine at a given $x / D_{p}$ position.

The equation used to curve fit the experimental temperature profile for the case with a cold secondary is

$$
G_{T}(r)=F\left(r, B_{T_{P}}, \delta_{T}\right)_{P}
$$

The constants used were determined by curve fitting data given in Ref. 10 and they are shown in Table I. The temperature profile used for the case with a hot secondary is similar to that used for the velocity profile

$G_{T}(r)=\left(1-\frac{T_{s}}{T_{p}}\right) F\left(r, B_{T_{p}}, \delta_{T}\right)+\frac{T_{S}}{T_{p}} F\left(r, B_{T_{s},{ } T_{S}}\right)$

Again, just as for the velocity profiles the actual velocity profile used for this case is normalized by $\mathrm{G}_{T}(0)$.

$$
\frac{T(r)-T_{\infty}}{T_{c l x}-T_{\infty}}=\frac{G_{T}(r)}{G_{T}(0)}
$$

Again the constants used were determined by curve fitting data given in Ref. 10 and they are shown in Table I.

The momentum loss boundary layer thickness, $\theta_{c}$, is used as the characteristic of the free jet shear layer. For compressible flow, it is defined as follows:

$$
{ }_{c}{ }_{c}=\int_{0}^{\infty} \frac{\rho(r)}{{ }^{\rho}{ }_{c l x}} \frac{\bar{U}(r)}{\bar{U}_{c l x}}\left(1-\frac{\bar{\sigma}(r)}{\bar{U}_{c l x}}\right) d r
$$

Note, however, that the incompressible momentum boundary layer thickness defined as

$$
\theta=\int_{0}^{\infty} \frac{\bar{U}(r)}{\sigma_{c \backslash x}}\left(1-\frac{\bar{U}(r)}{\sigma_{c l x}}\right) d r
$$

is more frequently used to characterize the thickness of the velocity shear layer for jet shear layer instability studies even for compressible flow. 12 Consequently, it is used again in this paper.

\section{Linearized disturbance equations}

The disturbance equations are derived by introducing small disturbances $u^{\prime}, v^{\prime}, w^{\prime}, p^{\prime}, \rho^{\prime}$ into the equations of momentum and mass conservation and keeping only the linear terms. The equations are linearized about the basic jet flow which is assumed to be locally parallel with $U(r)$ being the axial velocity component of the undisturbed flow. The Reynolds number of the flow is assumed to be large so that the flow is inviscid. The flow is also assumed to be isentropic.
The disturbance is assumed to be a spatially growing wave of the type

$$
\begin{array}{r}
{\left[u^{\prime}, v^{\prime}, w^{\prime}, p^{\prime}, \rho^{\prime}\right]=[u(r), v(r), w(r), p(r), \rho(r)]} \\
\exp \left[i\left(\alpha x-m_{\varphi}-\beta t\right)\right]
\end{array}
$$

where the radian frequency, $\beta$, and the integer azimuthal wave number, $m$, are real, while the eigenvalue wavenumber, $\alpha$, is complex. The real value of $\alpha, \alpha_{r}$ is the axial wave number. The imaginary value of a determines the spatial growth rate, $-\alpha j$. If $-a j$ is greater than zero the wave defined by Eq. (9) grows as it propagates. The propagation phase velocity $C_{p h}$ is given by $B / a_{r}$.

Using Eq. (9), the disturbance equations can be reduced to a single equation for the pressure perturbation $p(r)$ :

$$
\begin{aligned}
L(p)=\frac{d^{2} p}{d r^{2}}+\left\{\frac{1}{r}\right. & \left.-\frac{2}{[\bar{U}(r)-\beta / \alpha]}\right\} \frac{d U(r)}{d r} \frac{d p}{d r} \\
& -\left[\alpha^{2} \lambda^{2}(r)+m^{2} / r^{2}\right] p=0
\end{aligned}
$$

where

$$
\lambda^{2}(r)=1-\left[\frac{\bar{U}(r)-\beta / \alpha}{a}\right]^{2}
$$

and $a$ is the acoustic speed of sound. Equations of this form for the fluctuating pressure are well known and given in Refs. 15 and 16.

Near the jet axis $(r \rightarrow 0)$ and in the ambient fluid far from the jet $(r+\infty)$ the velocity profile, $U(r)$, is constant and $\mathrm{dU}(r) / \mathrm{dr}$ is zero. In these regions $\mathrm{Eq}$. (10) reduces to a form of the Bessel equation. Consequently, the asymptotic solutions to $E_{q} .10$ are given by the modified Bessel functions $I_{m}$ and $K_{m}$ of order $m$. The boundary conditions for the pressure require that $p(0)$ has to be bounded and $p(\infty)$ has to be zero. Hence, near the jet axis $(r+0)$

$$
p(r) \cong I_{m}[\alpha \lambda(r) r]
$$

and in the ambient fluid $(r+\infty)$

$$
p(r) \cong K_{m}(\alpha \lambda(r) r)
$$

The numerical procedure used to solve the eigenvalue problem is a shooting method similar to that described in Ref. 15. Another method based on a finite difference scheme has been recently developed. ${ }^{2} 1$ Both methods give similar results when applied to the same test problems. However, near the neutral stability point, convergence is a problem with the shooting method. The step size must be reduced until one is sure that the result is independent of this parameter in order to be sure the shooting method has produced a valid result.

The differential Eq. (10) is scaled using the incompressible momentum boundary shear layer thickness, $\theta$, and the velocity difference $\Delta U$, between the jet centerline velocity at a particular $x / D_{p}$, $\bar{U}_{C l x}$, and the ambient jet velocity, $\bar{U}_{\infty}$. For the case studied, $\Delta U$ is the jet centerline velocity, 
$\overline{\mathrm{U}}_{\mathrm{Clx}}$, since the ambient velocity is zero. The resulting differential equation then depends on two normalized parameters, the dimensionless spatial growth rate $-\alpha ; \theta$ and the dimensionless frequency, $B \theta / \Delta U$.

The complex differential equation written as a first order vector system is integrated numerically by a Runge-Kutta procedure. The infinite integration region is divided into two finite regions, an inner region $r_{0}<r<r h$ and an outer region $r_{h}<r<r_{\infty}$. The values of $r_{0}$ and $r_{\infty}$ are chosen such that $\mathrm{dU} / \mathrm{dr}$ is small and the integration of Eq. (10) can be started at these points.

In the inner region

$$
P_{0}(r)=f_{0}(r)
$$

where $f_{0}(r)$ represents the numerical Runge-Kutta solution in the inner region. In the inner region the numerical integration goes from $r_{p}$ toward $r_{h}$. Near the origin the proper initial condition for the Runge-Kutta integration from $r_{0}$ to $r_{h}$ is from Eq. (11)

$$
P_{0}\left(r_{0}\right)=I_{m}\left[\alpha \lambda\left(r_{0}\right) r_{0}\right]
$$

In the outer region the numerical Runge-Kutta solution is given by

$$
P_{0}\left(r_{0}\right)=c_{e} f_{e}(r)
$$

In contrast to the inner region, this Runge-Kutta solution is obtained by integrating from $r_{\infty}$ toward the origin. Far from the jet from Eq. (12) the proper initial condition for the Runge-Kutta integration from $r_{\infty}$ to $r_{h}$ is

$$
P_{e}\left(r_{\infty}\right)=C_{e} K_{m}\left[\alpha \lambda\left(r_{\infty}\right) r_{\infty}\right]
$$

The eigenvalue is determined by an iterative procedure. The eigenvalue is the value of $a$ which makes $p$ and $d p / d r$ continuous at $r=r_{h}$. Hence, the eigenvalue equation for $\alpha$ is

$H(\alpha)=f_{0}\left(r_{h}\right) \frac{d f_{e}\left(r_{h}\right)}{d r}-\frac{f_{e}\left(r_{h}\right) d f_{0}\left(r_{h}\right)}{d r}=0$

where $f_{0}$ and $C_{e} f_{e}$ are the solutions in the inner and outer regions. The constant $C_{e}$ is determined by the condition that at $r_{h}$ the inner and outer pressure eigenfunction solutions have the same value.

The eigenvalue is determined in a two step procedure. The first step uses a technique employed in Ref. 22. The technique is based on a theorem in complex variable theory which states that the number of zeros within a closed contour equals the net multiples of $2 \pi$ by which the phase angle of $H(\alpha)$ changes around the contour. 23 This method is extremely powerful since by using $i t$, one can be sure one has found the most unstable eigenvalue. The method also yields an accurate initial guess. The initial guess is then used by a least squares function minimization iterative procedure, which finds the eigenvalue.

\section{Results}

Calculated axisymmetric $(m=0)$ and azimutha $(m=1)$ spatial growth rates and phase velocities at $x / D_{p}=1$ for a two-stream coplanar jet with a secondary to primary velocity ratio of 0.68 and for both cold and hot secondary flows are shown in Figs. 3 and 4 . Also shown are results presented in Ref. 11 obtained at $x / 0=1$ for $m=0$ and $m=1$ for a two-stream coplanar jet with a secondary to primary velocity ratio 0.3 with cold secondary flow. At $x / D_{p}=1$ the boundary layer thickness for the case where the velocity ratio is 0.3 is $0.899 \mathrm{~cm}$. The boundary layer thickness for the cases where the velocity ratio is 0.68 is $5.11 \mathrm{~cm}$ when the secondary flow is cold and $3.08 \mathrm{~cm}$ when it is hot. The nozzle geometry for all cases is identical. Figure 3 shows the dimensionless spatial growth rate, $-\alpha_{i}, \theta$ as a function of the dimensionless frequency, $\beta \theta / \Delta u$, for the axisymmetric $(m=0)$ disturbance and for the first order azimuthal $(m=1)$ disturbance. At all frequencies, for a velocity ratio of 0.68 , the axisymmetric and the first order azimuthal disturbances have nearly identical growth rates. Furthermore, the magnitude of the growth rate for the case of cold secondary flow is much greater than that of the case with hot secondary flow. Note that the spatial growth rate with a velocity ratio of 0.68 is greater than that for a velocity ratio of 0.3 .

For the cold secondary rase with a jet velocity ratio of 0.3 , the preferred excitation Strouhal number is 0.05 . However, the growth rate is very low. For this case it is better to excite the first order azimuthal mode at a Strouhal number of 0.45 . For the case with a velocity ratio of 0.68 and for both modes, the case with a heated secondary flow has its largest growth rate at a Strouhal number of 0.2 . However, the case with the cold secondary flow has its largest growth rate at a Strouhal number of 0.4 .

In Fig. 4 the axial phase velocity, $c_{\mathrm{ph}}=\beta / \alpha_{r}$, for $X / D=1$ is plotted as a function of the frequency for $m=0$ and $m=1$. For $a$ single jet the phase velocity of the axisymmetric disturbance $(m=0)$ always decreases with increasing frequency from the jet velocity $\bar{U}_{c l x}$ at zero frequency. Also, for a single jet the phase velocity of the first azimuthal disturbance is always less than the phase velocity of the axisymmetric one. 6 For the two-stream axisymmetric jet, the frequency dependence of the phase velocities of the axisymmetric and first azimuthal disturbances are similar to those of a single jet. 6 For a velocity ratio of 0.68 , the phase velocity is lower if the secondary is hot for the axisymmetric and first order azimuthal case. Note that the phase velocity for the case with a velocity ratio of 0.68 is lower than for the case where the velocity ratio is 0.3 .

\section{Concluding Remarks}

It has been shown that the instability characteristics of the two-stream axisymmetric jet with a secondary to primary velocity ratio of 0.68 are different from those obtained for a secondary to primary velocity ratio of 0.3 . For example, for cold secondary flow with a jet velocity ratio of 0.3 , the growth rate of the axisymmetric mode 
$(m=0)$ is much less than the growth rate of the first order azimuthal mode $(m=1)$. While for cold or hot secondary flow with a jet velocity ratio of 0.68 . The growth rates of the axisymmetric mode $(m=0)$ and first order azimuthal mode $(m=1)$ are equal.

The presence of the heated secondary stream reduced the instability of both modes. For a twostream, coplanar jet operating at a secondary to primary velocity ratio of 0.68 aero/mechanical excitation can be designed to excite either mode.

\section{References}

1. Stone, J.R.; and Mckinzie, D.J. Jr.: Acoustic Excitation-A Promising New Means of Controlling Shear Layers. NASA TM-83772 1984.

2. Tanna, H.K.; and Ahuja, K.K.: Tone Excited Jets, Part I: Introduction. J. Sound Vib., vol. 102, no. 1, Sept. 8, 1985, pp. 57-61.

3. Ahuja, K.K.; and Whiffen, M.C.: Tone Excited Jets, Part II: Flow Visualization. J. Sound Vib., vol. 102, no. 1, Sept. 8, 1985, pp. 63-69.

4. Lepicovsky, J.; Ahuja, K.K.; and Burrin, R.H.: Tone Excited Jets, Part III: Flow Measurements. J. Sound Vib., vol. 102, no. 1, Sept. 8, 1985, pp. 71-91.

5. Ahuja, K.K.; and Blakney, D.F.: Tone Excited Jets, Part IV: Acoustic Measurements. J. Sound Vib., vol. 102, no. 1, Sept. 8, 1985, pp. 92-117.

6. Tam, C.K.W.; and Morris, P.J.: Tone Excited Jets; Part V: A Theoretical Model and Comparison with Experiment. J. Sound Vib., vol. 102, no. 1, Sept. 8, 1985, pp. 119-151.

7. Scott, J.; and Hankey, W.: Numerical Simulation of Unsteady Flow in an Axisymmetric Shear Layer. AIAA Paper 86-0202, Jan. 1986.

8. Raman, G.: Enhanced Mixing of an Axisymmetric Jet by Aerodynamic Excitation. NASA CR-175059, 1986.

9. von Glahn, U.H.: On Some Flow Characteristics of Conventional and Excited Jets. AIAA Paper 84-0532, Jan. 1984.

10. von Glahn, U.; Goodykoontz, J.; and Wasserbauer, C.: Velocity and Temperature Characteristics of Two-Stream, Coplanar Jet Exhaust Plumes. AIAA Paper 84-2205, Aug. 1984.
11. Miles, J.H.: Spatially Growing Disturbances in a Two-Stream, Coplanar Jet. AIAA Paper 86-0041, Jan. 1986.

12. Michalke, A.: Survey on Jet Instability Theory. Prog. Aerospace Sci., vol. 21, no. 3, 1984, pp. 159-199.

13. Crighton, D.G.: Instability and Acoustic Properties of Coaxial Jets. Bull. Am. Phys. vol. 29 , no. $4,1985$.

14. Michalke, A., and Hermann, G.: On the Inviscid Instability of a Circular Jet with External Flow. J. Fluid Mech., vol. 114, Jan. 1.982, pp. 343-359.

15. Michalke, A., Instability of a Compressible Circular Free Jet with Consideration of the Influence of the Jet Boundary Layer Thickness. (Instibilitat eines kompressiblen runden Frestrah1s unter Berucksichtigung des Einflusses der Strahlgrenzschichtdicke. Zeitschrift fur Flugwissenchaften vol. 19, no. $8 / 9,1971$, pp. 319-328). NASA-TM-75190, 1977 .

16. Morris, P.J.: Flow Characteristics of the Large Scale Wave-Like Structure of a Supersonic Round Jet. J. Sound Vib., vol. 53, no. 2 , July 22, 1977, pp. 223-244.

17. Morris, P.J.: The Spatial Viscous Instability of Axisymmetric Jets. J. Fluid Mech., vol. 77 , pt. 3, Oct. 8, 1976, pp. 511-529.

18. Crighton, D.G.; and Gaster, M.: Stability of Slowly Diverging Jet Flow. J. Fluid Mech., vol. 77, pt. 2, Sept. 24, 1976, pp. 397-413.

19. Plaschko, P.: Helical Instabilities of Slowly Diverging Jets. J. Fluid Mech., vol. 29, pt. 2, May 28, 1979, pp. 209-215.

20. Stromberg, J.L.; McLaughlin, D.K.; and Troutt, T.R.: Flow Field and Acoustic Properties of a Mach Number 0.9 Jet at Low Reynolds Number. J. Sound Vib., vol. 72, no. 2, Sept. 22, 1980, pp. 159-176.

21. Paragiri, R.: The Stability Analys is of Axisymmetric Jets. Master Thesis; University of Arizona, 1985.

22. Lessen, M.; Sadler, S.G.; and Liu, T.-Y.: Stability of Pipe Poiseuille Flow. Phys. Fluids, vol. 11, no. 7 , July 1968 , pp. 1404-1409.

23. Kaplan, W.: Operational Methods for Linear Systems. Addison-Wesley, 1962, pp. 157-158. 
TABLE I. - JET TEST CONDITIONS AND PROFILE PARAMETERS

(a) Cold Secondary Flow

\begin{tabular}{|c|c|c|c|c|c|c|c|c|c|c|c|}
\hline \multicolumn{8}{|c|}{ 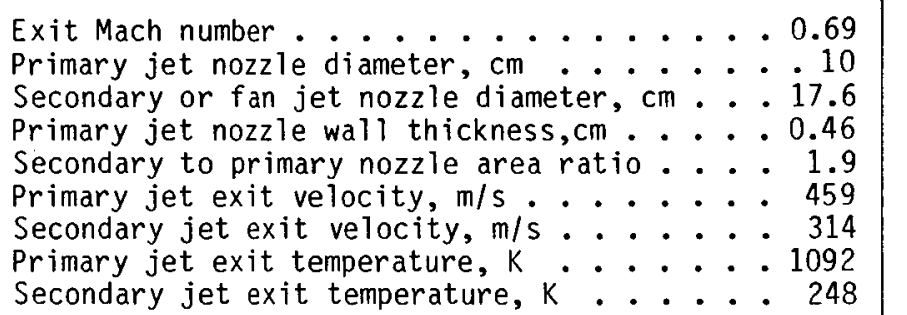 } & & & & \\
\hline$x / 0_{p}$ & $R_{p} / \theta$ & $\begin{array}{l}\theta \\
\mathrm{cm},\end{array}$ & ${ }^{\theta} \mathrm{c}$, & $\begin{array}{c}\mathrm{O}_{\mathrm{clx}}, \\
\mathrm{m} / \mathrm{s}\end{array}$ & $\mathrm{T}_{\mathrm{K}} \mathrm{l}_{\mathrm{x}}$, & ${ }^{B} U_{p}$ & ${ }^{\delta} U_{p}$ & ${ }^{B} U_{S}$ & ${ }^{\delta} U_{S}$ & ${ }^{B} T_{p}$ & ${ }^{\delta} U_{p}$ \\
\hline $\begin{array}{l}1 \\
2 \\
4 \\
8 \\
12.75\end{array}$ & 1 & 5.11 & 1.32 & $\begin{array}{l}459 \\
459 \\
433 \\
369 \\
290\end{array}$ & $\begin{array}{l}1092 \\
1081 \\
1062 \\
693 \\
403\end{array}$ & $\begin{array}{l}10 \\
5 \\
5 \\
2 \\
1\end{array}$ & $\begin{array}{r}0.8 \\
.6 \\
.6 \\
.6 \\
.7\end{array}$ & $\begin{array}{r}20 \\
8 \\
5 \\
3 \\
4\end{array}$ & $\begin{array}{r}1.9 \\
1.8 \\
2 \\
2.2 \\
.3\end{array}$ & $\begin{array}{l}6 \\
6 \\
3 \\
.8 \\
.8\end{array}$ & $\begin{array}{r}0.7 \\
.8 \\
.5 \\
.3 \\
.3\end{array}$ \\
\hline
\end{tabular}

(b) Hot Secondary Flow

Exit Mach number ........... 0.71

Primary jet nozzle diameter, cm ..... 10

Secondary or fan jet nozzle diameter, $\mathrm{cm}$. . 17.6

Primary jet nozzle wall thickness, cm . . . 0.46

Secondary to primary nozzle area ratio . . 1.9

Primary jet exit velocity, $\mathrm{m} / \mathrm{s}$...... . 459

Secondary jet exit velocity, $\mathrm{m} / \mathrm{s} . . .2 . .314$

Primary jet exit temperature, $K$. . . . . 1050

Secondary jet exit temperature, $k$..... 545

\begin{tabular}{|c|c|c|c|c|c|c|c|c|c|c|c|c|c|}
\hline$x / D_{p}$ & $R_{p} / \theta$ & $\begin{array}{c}\theta \\
\mathrm{cm}\end{array}$ & $\begin{array}{l}{ }^{\theta} \mathrm{c}, \\
\mathrm{cm}\end{array}$ & $\begin{array}{c}\sigma_{c i x}, \\
m / s\end{array}$ & $\mathrm{~T}_{\mathrm{K}} \mathrm{K}_{\mathrm{X}}$, & ${ }^{B} U_{p}$ & ${ }^{\delta} U_{p}$ & ${ }^{B} U_{s}$ & ${ }^{\delta} U_{S}$ & ${ }^{\mathrm{B}} \mathrm{T}_{\mathrm{p}}$ & ${ }^{\delta} \mathrm{T}_{\mathrm{p}}$ & ${ }^{B} T_{S}$ & ${ }^{\delta} \mathrm{T}_{\mathrm{S}}$ \\
\hline $\begin{array}{l}1 \\
2 \\
4 \\
8 \\
12.75\end{array}$ & 1 & 3.08 & 1.19 & $\begin{array}{l}459 \\
459 \\
459 \\
415 \\
274\end{array}$ & $\begin{array}{r}1050 \\
1050 \\
1050 \\
883 \\
633\end{array}$ & $\begin{array}{r}20 \\
5 \\
5 \\
2 \\
3\end{array}$ & $\begin{array}{r}0.9 \\
1.1 \\
.9 \\
.6 \\
1.3\end{array}$ & $\begin{array}{r}10 \\
8 \\
2 \\
2 \\
1\end{array}$ & $\begin{array}{l}1.8 \\
1.9 \\
1.8 \\
1.6 \\
2.3\end{array}$ & $\begin{array}{c}10 \\
5 \\
2 \\
2 \\
.7\end{array}$ & $\begin{array}{r}0.9 \\
.9 \\
.7 \\
.7\end{array}$ & $\begin{array}{c}10 \\
5 \\
4 \\
2 \\
.7\end{array}$ & $\begin{array}{l}1.7 \\
1.7 \\
1.7 \\
2 \\
2\end{array}$ \\
\hline
\end{tabular}





(B) HOT SECONDARY; $T_{p}, 1050 \mathrm{~K}, \mathrm{~T}_{\mathrm{s}}, 545 \mathrm{~K}$; $\overline{\mathrm{U}}_{\mathrm{p}}, 459 \mathrm{~m} / \mathrm{s}$; $\overline{\mathrm{U}}_{\mathrm{S}} \cdot 314 \mathrm{M} / \mathrm{s}$.

FIGURE 1.- COMPARISON OF CALCULATED AND MEASURED RADIAL VELOCITY PROFILES FOR: $\bar{U}_{S} / \bar{U}_{P}$ RATIO OF 0.68: NOZZLE AREA RATI0, 1.9 . 


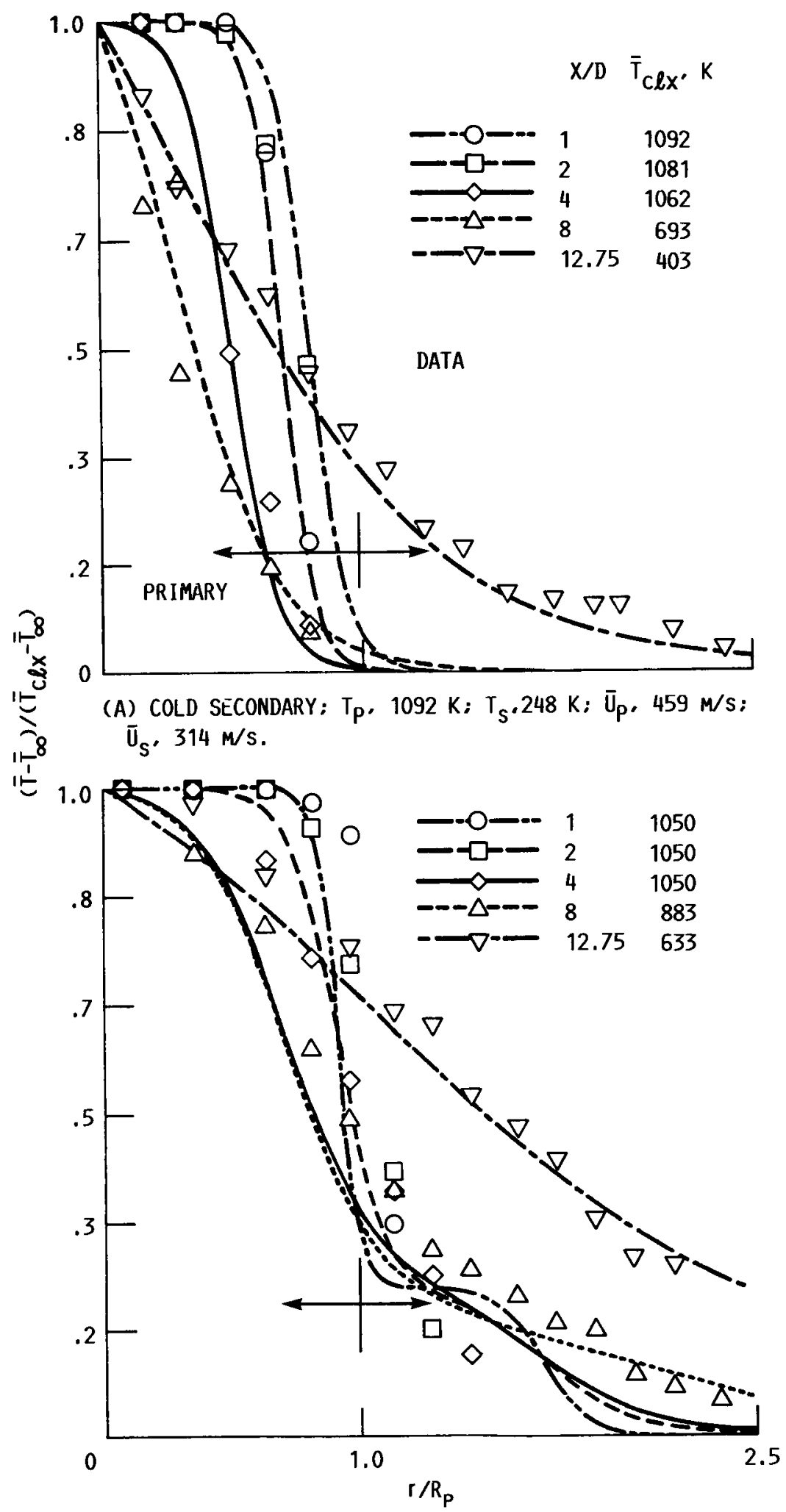

(B) HOT SECONDARY; $T_{p}, 1050 \mathrm{~K}: \mathrm{T}_{\mathrm{s}}, 545 \mathrm{~K} ; \bar{U}_{p}, 459 \mathrm{~m} / \mathrm{s}$ : $\overline{\mathrm{U}}_{\mathrm{S}} \cdot 314 \mathrm{M} / \mathrm{S}$.

FIGURE 2.- COMPARISON OF CALCULATED AND MEASURED RADIAL TEMPERATURE PROFILES FOR: $\bar{U}_{\mathrm{S}} \overline{\mathrm{U}}_{\mathrm{P}}$ RATIO OF 0.68: NOZZLE AREA RATI0, 1.9. 


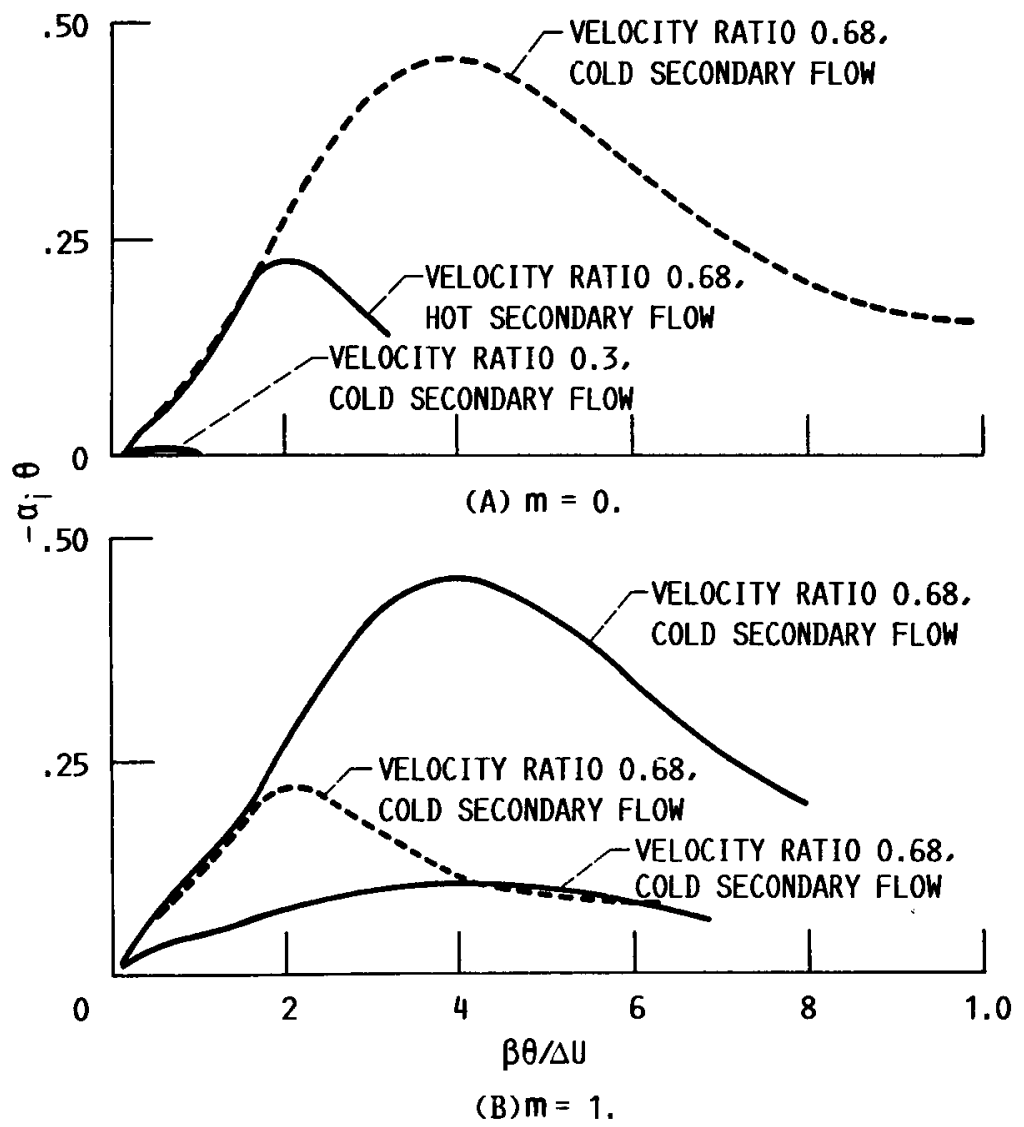

FIGURE 3.- SPATIAL GROWTH RATE OF THE AXISYMMETRIC $(m=0)$ AND FIRST AZIMUTHAL $(m=1)$ DISTURBANCE AT $X / D=1$. 


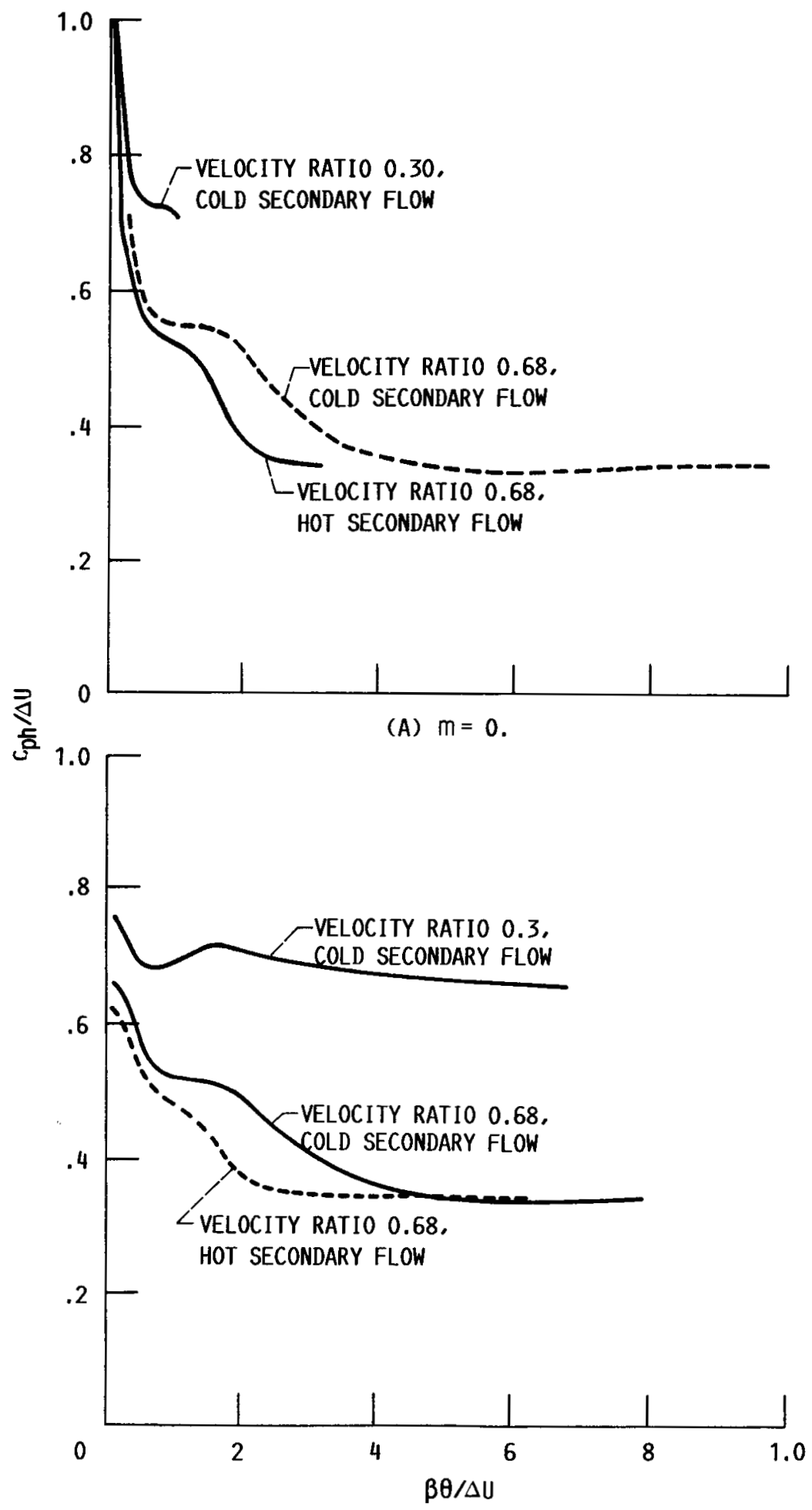

(B) $m=1$.

FIGURE 4.- AXIAL PHASE VELOCITY OF THE AXISYMMETRIC $(m=0)$ AND FIRST AZIMUTHAL $(m=1)$ DISTURBANCE AT $X / D=1$. 


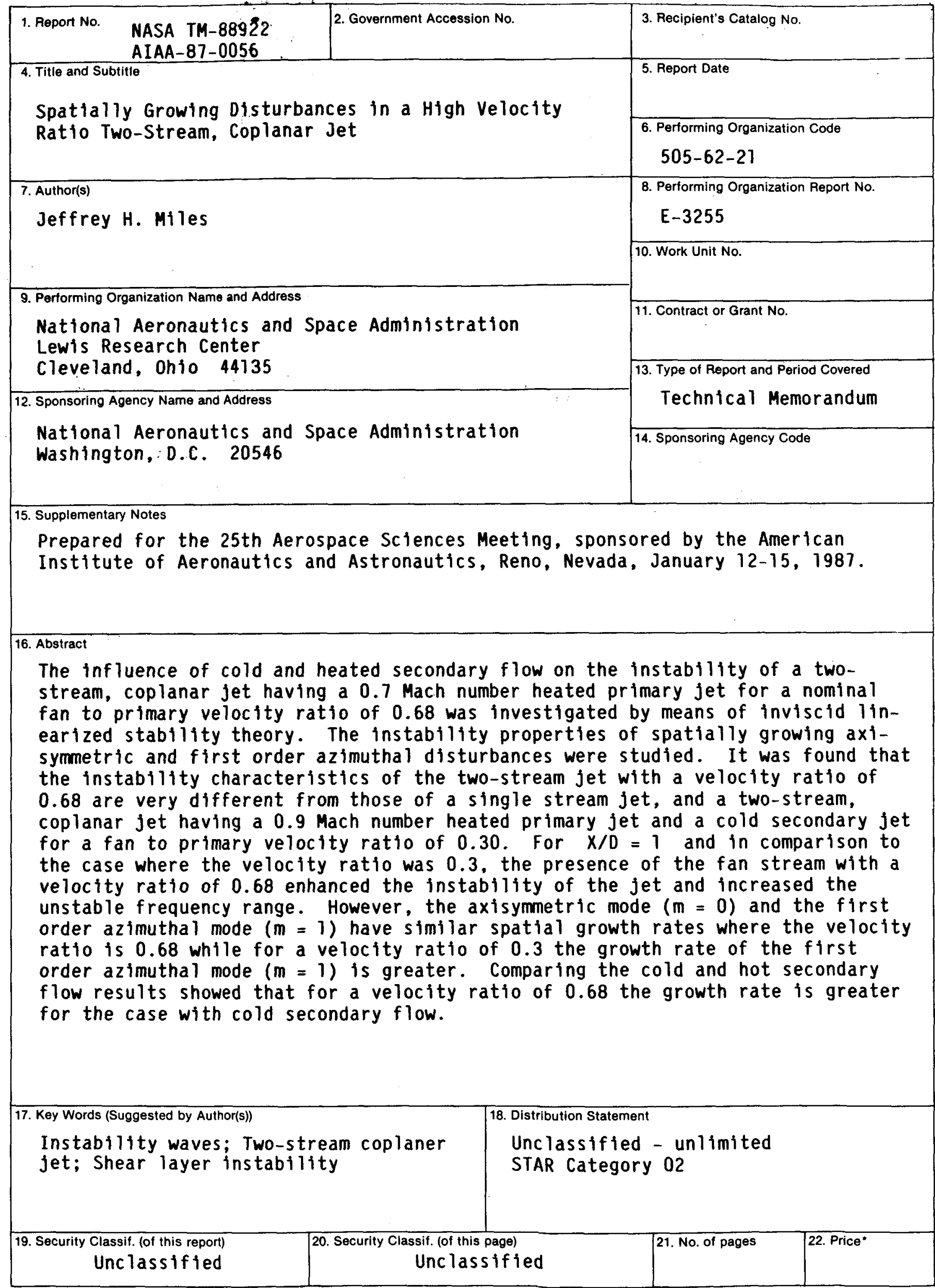

*For sale by the National Technical Information Service, Springfield, Virginia 22161 